obtained by cryoscopic measurements of osmotic values.

Prof. A. Bonne (Israel) and Dr. M. Ezekiel (F.A.O.) presented the point of view of the economist and explained the importance both of economic planning and of general economic and statistical surveys of food requirements. Prof. M. R. Huberty (F.A.O.) explained the structure and purpose of the Food and Agriculture Organization with special reference to its activities in the field of ground-water studies.

Introductory to the excursions, Mr. P. L. O. Guy (Israel) gave an account of the remnants of the soil and water conservation service which existed in the Kurnub upper-catchment area during the Byzantine period and suggested that the site should be rebuilt as an experimental reserve; Mr. A. de Leeuw (Israel) outlined the overall irrigation scheme for Israel with special emphasis on the problem of water storage.

In the session held in Haifa, Mr. E. W. Golding (Great Britain) told of recent British experience on the utilization of wind-power for the generation of electricity by windmills of modern type, and gave a general discussion on the economic exploitation of wind energy with particular reference to this region. The remaining papers of the last day dealt with problems of ground water and water in soils. Dr. P. Danel (France) dealt with the physics and the measurements of the flow of ground water and with the application of the methods of measurement which he and his co-workers in Grenoble had developed. Dr. L. A. Richards's (United States) papers also dealt largely with the technique of measurements, in this case with the physical properties of soils, especially as regards their power to retain water. The relevance of such measurements to irrigation methods was discussed, as well as the foundations of the new subject of soil physics. The paper of Dr. A. N. Khosla (India) was read by his colleague, Dr. R. D. Dhir, and dealt with the relation of surface water and ground water in arid zones. He gave a simple formula which he has applied successfully to several catchment areas in India to determine the yearly run-off from catchment areas. The formula is based on monthly average temperatures only. In the discussion it was pointed out that Dr. Khosla's method may be correlated to Thornthwaite's method of evapo-transpiration. Prof. L. Pjcard (Israel) reviewed the history of ground-water investigations, and Dr. M. G. Drouhin (Algiers) spoke on hydrological studies in desert regions.

In the closing session Sir Ben Lockspeiser (Great Britain) summed up his impressions of the conference, followed by a discussion to which, among others, Kellogg and Monod made valuable contributions. It appears that the main lessons to be learned from this symposium are as follows: (1) Desert research requires many disciplines, and although men of science usually prefer to talk to specialists in their own discipline, a conference of this type bringing together the various experts dealing with arid zones is valuable and should be repeated every four or five years. (2) In all the branches men of science are still struggling to clarify their ideas; in some of them even commonly accepted definitions and terminology are still lacking. Nevertheless, (3) the biggest hindrance to progress at the present time is the lack of available data in branches where there is common agreement on which data should be assembled, and there are generally accepted techniques for assembling them. This is true particularly for soil and water studies and also for certain specialized meteorological data. The members of the conference unanimously accepted the following resolutions :

"This symposium wishes to draw the attention of the Director-General of Unesco to the following resolutions :

"1. That interested Governments be invited to strengthen existing research devoted to various problems of arid zones at existing national centres with a view to $(a)$ encouraging fundamental research, and $(b)$ the eventual creation of national bodies where the practical problems of each area can be brought to a focus and considered as a whole.

" 2 . That the effort devoted to field surveys, undertaken to obtain the basic data on the arid zones, should be extended and means provided for increased training facilities for technical personnel required for field studies and operations.

"3. The symposium attaches great importance to the exchange of scientists and the sharing of training facilities on an international basis.

" 4 . The symposium appreciates the practical interest and support of arid zone research and development of the United Nations, its Specialised Agencies and of international non-governmental scientific organizations, and warmly supports the recommendation of the Advisory Committee on Arid Zone Research that Unesco should initiate steps for the preparation of a handbook to guide collection of basic data".

The proceedings of the symposium will be published by the Research Council of Israel with financial support by Unesco.

S. GoLdstern

\section{THE SCIENCE OF DOMESTIC HEATING*}

$T$

HE subject of domestic heating is of particular interest at the present time in Great Britain when the quantity of coal for use in homes may well have to be reduced as a result of both the everincreasing demand for coal to satisfy the expanding power requirements of industry and the urgent economic need to export more coal.

Coal must continue to be the principal domestic fuel in Britain for many years to come, the supply of alternative fuels being totally inadequate for this purpose, so that there is every incentive to improve heating methods 'and appliances with the view of obtaining more heat and comfort from less coal. Furthermore, the greater scarcity of coal and its rising cost, together with an advance of scientific techniques and equipment, have given an added impetus to a more scientific approach to the problem during recent years.

The chimney fireplace was first introduced into England during Norman times and was the beginning of the familiar open fire of to-day. The early chimneys were large and troublesome; but their size was reduced only slowly, and it was not until Rumford suggested a narrowing of the throat of the fire, to reduce room draughts and to combat down-draught, that any marked improvement occurred. A further restriction of the throat, with consequent additional advantage, followed upon the introduction of cast iron as a

* Summary of a Friday Evening Discourse delivered to the Royal Institution on May 16 by Mr. J. S. Hales, of the British Coal Utilisation Research Assorlation. 
material of fireplace construction; but this advance was lost later when the tile surround became popular and precluded the use of proper throat control. Cold draughts increased again, furnishings and clothing became lighter, and comfort decreased once more.

It is not always appreciated that, of the heat available in coal burned in an ordinary stool-bottom grate in a tile surround, only some $20-25$ per cent is emitted as useful heat in the form of radiation. Of the remaining heat, up to 20 per cent passes into the brickwork of the fireplace, and the rest is lost in the flue gases, which include smoke, and in any unburned fuel in the ashes. If the chimney is on an inside wall, a proportion of the heat lost into the brickwork and in the flue gases may be regained, but the amount is small because of the low temperature of the flue gases, caused by their admixture with excessive air drawn into the unrestricted throat of the fire. Attempts have been made, from the seventeenth century onwards, to make better use of the heat which passes into the brickwork of an ordinary open fire, usually by the design of so-called 'convector' fires, in which the fire is partially enclosed within a metal casing. Air circulates through the annulus so formed, and is heated before re-entering the room. Modern types of convector fire are continuously burning and incorporate underfloor air-control for the rapid revival of 'dead' fires.

Although comparatively inefficient, the open coal fire has the redeeming feature of attractiveness, which is doubtless the principal reason for its retention in homes. To be fully acceptable, however, the open fire must provide an optimum degree of comfort combined with an economical use of coal.

Comfort may best be defined as the simulation indoors of the outdoor conditions on a calm, sunny day in spring-namely, a source of radiation, a moderate air temperature, no excessive air movement and a reasonable humidity of the air. The economical attainment of this degree of comfort demands that greater attention be paid to existing methods of house-building. A source of radiant heat alone cannot give the desired room air temperature, while purely convection heating, which tends to require the maintenance of high air temperatures, leads to a high heat loss and consequent heavy fuel consumption in the vast majority of present-day British houses. This heat loss can only be reduced by careful insulation of walls, ceilings and windows, and by the exclusion of unnecessary draughts. Unfortunately, satisfactory insulation is impossible in most existing houses, so that a compromise between solely radiant and purely convective heating methods needs to be effected.

Such compromises have been proposed for as long as two hundred years, for the cheminée de Nancy was in effect an open fire which provided convection heating also. Modern appliances still seek to provide radiant and convective heating, and also to reduce the air flow up the chimney to the acceptable figure of about $2,500 \mathrm{cu}$. ft. $/ \mathrm{h}$. for average rooms and occupancy.

The many earlier proposals for better house-heating may have been neglected because of a lack of proper testing equipment and facilities. These difficulties are now being removed, however, and in modern research into methods of domestic heating use is made of such instruments as the integrating radiometer, the continuous-recording balance, and the recording anemometer for the simultaneous measurement of the radiation, rate of fuel consumntion and air flow, respectively.
The outstanding problem of domestic fires, and one which will remain as long as coal is the chief fuel, is that of reducing or eliminating smoke emission. From the time when coal was first used as a fuel, suggestions have been made for reducing smoke, many of which require the smoke to pass through red hot cinders before its escape. Devices of this kind undoubtedly reduce smoke, but are difficult to develop as a controllable home appliance. Nevertheless, the attack on smoke has received added impetus from the recent development of precise measuring equipment, such as the thermal precipitator which measures the rate of deposition of tar or soot from flue gases.

The use of instruments of this type and those mentioned earlier, together with the application of modern techniques, should lead to a more rapid improvement in our methods of domestic heating which will remove many of the current criticisms to which we are subjected.

\section{BRITISH COLONIAL TERRITORIES, $1951-52$}

$T$ HE survey "The Colonial Territories 1951-52"*, which includes the usual chapter on research and surveys, again precedes the annual report on Colonial research and provides the essential background against which the recently published "Return of Schemes" made under the Colonial Development and Welfare Acts 1951-52 (see p. 311), and the annual report, "Colonial Research, 1951-52", still to appear, should be appraised. Considerable emphasis is again laid, in the general survey forming Part 1, on political developments, notably the new policy in Malaya, and the problems connected with closer association in Central Africa and with the coming into force of the new Nigerian constitution ; but, on balance, the main emphasis in the survey for this year is on economic matters. Financial stringency, for example, and the need to husband funds available for research schemes under the Colonial Development and Welfare Acts, have led to a marked decline in the number and size of research schemes made during, the year ; but some $£ 1,231,000$ was disbursed on such schemes during the year.

Recommendations by Colonial Governments for inclusion in the Colonial Research Service of more than sixty specialist and research posts in departments of agriculture and in veterinary services have been approved; some twenty new appointments were made on Colonial Research Service terms, and fifteen research studentships awarded. Nevertheless, there were still 988 vacancies in the Colonial Service in spite of 1,396 appointments during the year, and, of these vacancies, 281 were in the educational service, mainly for teachers of scientific and technical subjects and for primary teachers. Only 14I civil engineers and 68 mechanical engineers were recruited as against 169 and 70 , respectively, during 1950 , but 169 medical practitioners were recruited as against 131 for the previous year. The planned expansion of the Colonial Geological Surveys is now almost complete, with an overseas staff of 180, compared with 58 in 1947. In this field valuable help has also been given by United States and Canadian geologists, chemists and mining engineers under a scheme of the Economic Co-operation Administration, and, besides an increase

* Colonial office. The Colonial Territories, 1951-52. (Cmd. 8553.) Pp. $\mathrm{x}+140$. (London : H.M.S.0., 1952.) 48. 6d. net. 